\title{
Analysis of Entrepreneurial Intention of Agricultural University Students Under the Background of Agricultural Modernization
}

\author{
Kai Hou*, Xuhua Qiao \\ College of Agricultural Economics and Management, Shanxi Agricultural University, Taiyuan 030031, China. \\ * Corresponding author. Email: 2419719067@qq.com
}

\begin{abstract}
In the context of the development of agricultural modernization, this paper discusses the opportunistic entrepreneurial willingness of agricultural college students. Based on 531 questionnaires, empirical analysis of binary Logistics is conducted. It is concluded that entrepreneurial learning, attention to deeds, policy attention and family entrepreneurship all have positive effects on the increase of entrepreneurial willingness of agricultural college students, and gives relevant policy enlightenment.
\end{abstract}

Keywords: Agricultural modernization, Agricultural college students, Entrepreneurial intention, Rural revitalization.

\section{BACKGROUND AND SIGNIFICANCE OF THE STUDY}

The report to the 19th National Congress points out that issues concerning agriculture, rural areas and farmers are the top priority in the work of the whole Party. The implementation of the rural revitalization strategy is the focus of future work. An effective way to promote rural revitalization is to strengthen agricultural entrepreneurship, according to the No. 1 document issued by the central government in 2019. China will support and encourage college graduates to start businesses in the countryside. On April 29, 2021, the Law of the People's Republic of China on the Promotion of Rural Revitalization made it clear in the form of law that it supports and encourages graduates of agriculture-related institutions of higher learning to start businesses in rural areas. The entrepreneurship of college graduates can better play the role of advanced agricultural science and technology in agricultural production and accelerate the transformation of agricultural modernization. College students in agricultural universities are the important potential subjects for agricultural technology-oriented entrepreneurship, their entrepreneurial activities are the important carrier of the application and implementation of advanced agricultural science and technology. Under the background of promoting the strategy of rural revitalization and accelerating the development of agricultural modernization, it is of great practical significance to study the relationship between entrepreneurship education in agricultural colleges and the entrepreneurial intention of college students.

Existing literature only broadly analyzes entrepreneurship education, but does not analyze entrepreneurship education for agricultural college students, such as Li Linjie (2020), He Junxi (2019), Chen Cheng (2019), etc. Or although analyzed the entrepreneurial education in agricultural colleges and universities, but it is only based on the perspective of curriculum construction (Wang Wenlei et al., 2020) without introducing the macro perspective of rural revitalization and agricultural modernization transformation. Or just only qualitative analysis, lack of quantitative analysis of entrepreneurial intention of agricultural college students (Wang Zhixiong, Wang Qingcai et al., 2020). Therefore, this paper introduces the macro perspective of rural revitalization and agricultural modernization to make a quantitative analysis on the entrepreneurial willingness and entrepreneurship education of college students in agricultural colleges and universities, in order to make a marginal contribution to the existing literature. 


\section{THEORETICAL ANALYSIS}

The important feature of agricultural modernization is the full application of modern agricultural science and technology. Only by using advanced agricultural science and technology in agricultural production can the total factor productivity of agriculture be improved and the process of agricultural modernization be accelerated. Although ancient China has made brilliant achievements in agricultural science and technology, in modern times, China's agricultural science and technology tended to stagnate for a long period. As a whole, it lags behind the West, and has been in the development level of traditional agriculture for a long time. The excessive agricultural surplus labor force and the pre-modern traditional agricultural production technology locked in with each other, more and more labor input, but no improvement in agricultural productivity, it formed what Huang Zongzhi called-- the Involution. Since modern times, China, once a poor and weak country, has been subjected to aggression and exploitation by Western imperialist countries. People of vision in China have risen up against imperialist aggression and exploitation and actively introduced modern science and technology. With the introduction of agricultural science and technology, agriculture is slowly transforming towards modernization. Before the founding of the People's Republic of China, although there were some bright spots in agricultural science and technology, such as the production of ammonium sulfate fertilizer once reached the world's advanced level, but the cost was high, the scope of using was not widespread, and the overall development of agricultural modernization was quite slow. After the founding of the People's Republic of China, especially after the reform and opening up, under the leadership of the great Communist Party of China, China's agricultural modernization has really achieved rapid development. Advanced agricultural production technologies, such as the production and application of chemical fertilizers, mechanized agricultural production, water conservancy and irrigation construction, and the application of biotechnology, have all made unprecedented progress. Some agricultural technologies, such as hybrid rice, are leading the world and benefit other countries. However, due to the low starting point of development, China's agricultural modernization level still has a large room for improvement compared with other developed countries in the world. Under the new historical conditions, the realization of the Chinese Dream and rural revitalization has put forward more urgent requirements for the development of China's agricultural modernization.

Schumpeter believed that in order to achieve economic development, it was necessary to adopt new production technology, realize new combination of production factors, break the conventional circulation which at a low level in the past, and make the economic development entering a new track at a high level. Schumpeter called it innovation. Schulz believed that to transform traditional agriculture and make agriculture develop toward modernization, it is necessary to increase the investment of human capital and improve the education level of agricultural producers, which is the necessary guarantee of applying advanced agricultural science and technology and agricultural modernization. Traditional agriculture is mostly small-scale production, the scale of production is small, the use of old agricultural technology and long-term unchanged, agricultural productivity remains at a low level and hovering. In order to make agricultural development enter a new track of high level and transform traditional agriculture to develop modern agriculture, it is necessary to raise the educational level of agricultural producers. The goal of agricultural higher education is to train high-quality agricultural personnel who master advanced agricultural science and technology. On the one hand, through the investment of human capital, it can improve the application level of advanced science and technology in agricultural production and promote the development of agricultural modernization; On the other hand, the frontier and high-end of related subjects and research in agricultural higher education, as well as the free and active atmosphere in agricultural universities, can stimulate the courage and exploration spirit of students in agricultural universities, and inject subjective initiative into the development of agricultural modernization. A major feature of agricultural modernization is the market-oriented production (as opposed to the self-sufficiency of traditional small-scale agricultural production), this requires modern agricultural producers not only to master advanced agricultural science and technology, but also to have high management ability. Only by combining the two, they can realize value and create value in the fierce market competition. The continuous emergence of market competition winners will promote the spiraling rise of the level of agricultural modernization in macro.

If advanced agricultural science and technology build the core base of agricultural modernization, then innovation and entrepreneurial spirit put on the wings for flying in the sky of agricultural modernization. Therefore, market-oriented entrepreneurship education is of vital importance in agricultural colleges and universities, because it can foster the innovation and entrepreneurship that shape modern agricultural producers (Drucker, 2007).

China's higher education has entered the stage of mass education from elite education. More and more young people of the right age can enter the university campus to receive higher education, and agricultural higher education is naturally no exception. The differences in intelligence in the population basically show a normally distributed of bell curve, with low 
intelligence in the minority, high intelligence in the minority, and the vast majority of people in the middle. Without considering non-intellectual factors, in the period of higher education elitism, only a small number of students with high intelligence can receive higher education, when higher education became more common, more students of average intelligence were able to attend it. There is a difference between the growth rate of the number of students receiving higher education and that of the number of institutions of higher learning. The latter is slower than the former. There is a tension between the rapid growth of the number of students and the relatively fixed institutions of higher learning. There are more students at the top universities, and whereas previously only very intelligent students were admitted, now both very intelligent and relatively intelligent students are admitted; ordinary colleges and universities used to be entered by students with relatively intelligent, but now students with average intelligence can also enter. What has happened is that the popularization of higher education has led to a decline in the quality of students in ordinary colleges and universities compared with the past. High intelligence students have stronger understanding and self-study spirit, can draw inferences from one example; students with average intelligence need teachers to invest more energy and time in repeated explanations to help them grasp the basic knowledge. Therefore, on the premise of ensuring the quality of higher education, the popularization of higher education increases the difficulty of ordinary university. In the past, with the elitism of higher education, the state was able to implement national employment distribution for the small number of graduates under the system of planned economy. At present, with the popularization of higher education and the continuous improvement of the socialist market economy, a large number of graduates have to take the initiative to adapt to the demand of the market in order to win in the fierce competition in the job market. Even need to promote the spirit of entrepreneurship, through entrepreneurship to create jobs for others.

In the process of agricultural modernization and industrial structure upgrading, China still needs to transfer the surplus agricultural labor force and implement the new type of urbanization. The proportion of urban population and employed people in the secondary and tertiary industries will still rise for a certain period of time. At the same time, the problem of who will farm the land in the future has been highlighted to some extent. At present, most of those who are engaged in agricultural production in rural areas are elderly people, whose knowledge structure is aged and fixed and their ability to learn and accept new things is insufficient, which is not conducive to the application of advanced agricultural production technology. At the same time, agricultural colleges and research institutions generally have a low conversion rate of scientific and technological achievements, and national policies constantly emphasize that "papers should be written on the land", Its purpose is to emphasize application. This phenomenon is caused by many reasons, including the fragmentation of agricultural land management scale is not good for the implementation of advanced agricultural technology, also including the low level of education of traditional agricultural producers who are difficult to master how to use the advanced agricultural technology.

College students who receive agricultural higher education engage in agricultural production after graduation. Because they master advanced agricultural science and technology knowledge, it is conducive to the application of existing agricultural science and technology. Meanwhile, their knowledge structure is more perfect, and it has both demand and easy acceptance for high-end cutting-edge agricultural production technology. Combined with the market-oriented entrepreneurship education they have received, they can make more reasonable use of various factors of production, so that the factors of production can be combined in new ways under new technological conditions and create higher new values. The more such kind of people, the more can improve the scientific and technological content of agricultural production, the more can promote the process of agricultural modernization on the whole.

Compared with traditional producers, the graduates of agricultural universities have the advantage of agricultural science and technology knowledge. If the graduates of agricultural universities also have clear market awareness and entrepreneurial spirit, the combination of the two (technology knowledge and entrepreneurial spirit) will provide accelerated fuel for the development of agricultural modernization. This requires higher agricultural colleges to combine professional education with entrepreneurship education consistent with the law of economic development. When students in agricultural colleges and universities have entrepreneurial intention, it is possible to have entrepreneurial action. Although there is a certain distance between the intention and the behavior, having the intention is the logical basis for the actual action. Even if in a certain period of time there may be only intention and no action, but when the conditions are available, entrepreneurial intention will be transformed into actual entrepreneurial action. Of course, after the entrepreneurial actions, the entrepreneurial results also have the probability of success and failure, that is, the entrepreneurial performance also maybe good or bad. Entrepreneurial behaviors that do not conform to the law of economic development will naturally be eliminated by the market, leading to the failure of entrepreneurial results. Therefore, the entrepreneurship education consistent with the law of economic development is very important. 
What is the effect of entrepreneurship education in ordinary agricultural colleges at present? Can it improve the entrepreneurial intention of agricultural college students? What other factors affect the entrepreneurial intention of agricultural college students? These questions are the focus of this paper.

\section{DATA SOURCE AND MODEL SETTING}

The data came from a questionnaire survey of college students participating in entrepreneurship course, and the respondents were college students majoring in agriculture, including agriculture, plant protection, plant quarantine, bio-pharmaceutical and other related majors. A total of 540 questionnaires were collected, and 531 valid questionnaires were obtained after eliminating the missing data, with an effective rate of $98.3 \%$.

The entrepreneurial intention of agricultural college students was set as explained variable $\mathrm{Y}$, have entrepreneurial intention was 1 , and non-entrepreneurial intention was $0 ; \mathrm{X} 1$ is the gender of agricultural college students, male is 1 , female is 0 ; $\mathrm{X} 2$ is the source of agricultural college students, where the urban source is 1 and the rural source is $0 ; \mathrm{X} 3$ is the family economic status of agricultural college students, divided into five categories from less than 2,000 yuan to more than 50,000 yuan, and the values from low to high are 1 to 5 respectively; $\mathrm{X} 4$ is the degree of participation in entrepreneurship course of agricultural university students, and the degree of participation is 4 to 1 from high to low; X5 is the degree of attention of agricultural college students to entrepreneurial deeds, and the degree is 4 to 1 from high to low;X6 denotes the degree of attention of agricultural college students to entrepreneurship policy, and the degree is 4 to 1 from high to low; X7 refers to the entrepreneurial background of the family of agricultural college students. If neither of their parents was an entrepreneur, it is 0 ; if one of their parents was an entrepreneur, it is 1 ; if both of their parents are entrepreneurs, it is 2.

As the explained variable is a dichotomous variable, it can be used in the binary Logistic model. The basic form of the model is as follows:

$$
Y=\log \operatorname{it}(P)=\beta_{0}+\beta_{1} X 1+\beta_{2} X 2+\beta_{3} X 3+\beta_{4} X 4+\beta_{5} X 5+\beta_{6} X 6+\beta_{7} X 7
$$

$$
\text { Among them, } 1-P=\frac{1}{1+\exp \left(\beta_{0}+\sum_{i=1}^{7} \beta_{i} X i\right)}
$$

\section{DESCRIPTIVE STATISTICAL ANALYSIS}

Among the 531 questionnaires, 379 agricultural college students have entrepreneurial intention, accounting for $71.4 \%$; 152 college students have no entrepreneurial intention, accounting for $28.6 \%$; There are 280 female students, accounting for $52.7 \%$, and 251 male students, accounting for $47.3 \%$. The number of female students is more than that of male students. There are 366 students from rural areas, accounting for $68.9 \%$; there are 165 students from urban areas, accounting for $31.1 \%$. The majority of agricultural college students are from rural areas. In the family income of agricultural college students, the cumulative proportion of the monthly family income less than 10,000 yuan reached $94.5 \%$, and the cumulative proportion of the monthly family income less than 5,000 yuan reached $81.4 \%$, indicating that the vast majority of students come from middle and low-income families. The existence of the urban-rural economic dual structure makes the income level of urban families generally higher than that of rural families, and the agricultural college students surveyed in this survey are mostly from rural areas, so the middle and low-income families account for the majority. The proportion of agricultural college students whose parents have no entrepreneurs is $84.7 \%$, and the proportion of agricultural college students whose parents have one entrepreneur is $8.1 \%$. The proportion of agricultural college students whose parents are both entrepreneurs is $4.5 \%$, which shows that the vast majority of agricultural college students come from non-entrepreneurial families. Descriptive statistics of relevant variables are shown in Table 1: 
Table 1. Descriptive statistics

\begin{tabular}{|c|c|c|c|c|}
\hline variable & The minimum & The maximum & The mean & $\begin{array}{c}\text { The standard } \\
\text { deviation }\end{array}$ \\
\hline $\begin{array}{l}\text { YEntrepreneurial } \\
\text { intention }\end{array}$ & 0 & 1 & 0.71 & 0.45 \\
\hline $\mathrm{X} 1$ gender & 0 & 1 & 0.47 & 0.49 \\
\hline $\mathrm{X} 2$ Urban or rural & 0 & 1 & 0.31 & 0.46 \\
\hline $\begin{array}{l}\text { X3 Household } \\
\text { income }\end{array}$ & 1 & 5 & 1.85 & 0.88 \\
\hline $\begin{array}{l}\text { X4 Entrepreneurial } \\
\text { learning }\end{array}$ & 1 & 4 & 3.55 & 0.55 \\
\hline X5 Deeds attention & 2 & 4 & 2.75 & 0.69 \\
\hline X6 Policy concern & 1 & 4 & 2.43 & 0.71 \\
\hline $\begin{array}{l}\text { X7 Family } \\
\text { entrepreneur }\end{array}$ & 0 & 2 & 0.17 & 0.48 \\
\hline
\end{tabular}

\section{EMPIRICAL RESULTS ANALYSIS}

The results of empirical analysis are shown in Table

As can be seen from Table 2, the coefficient of influence of gender X1 on entrepreneurial willingness of agricultural college students is positive $(0.34)$, that is, male students have stronger entrepreneurial willingness than female students. Although gender has no significant influence, sig value still reaches $11 \%$, which is close to the significance level of $10 \%$. Entrepreneurship needs to break through the existing framework, take certain market risks and explore in the entrepreneurial fog. Compared with women, men are more adventurous, so men have a higher willingness to start a business. The results of this paper are similar to the conclusions of other studies.

It is generally believed that students from urban have a broader vision and more active thinking. They have been immersed in the prosperity of cities since childhood, and are more sensitive to the potential entrepreneurial opportunities in the market and have higher entrepreneurial willingness. However, the empirical research results of this paper do not confirm the above views. The difference between urban and rural areas of X2 has no significant influence on the entrepreneurial willingness of agricultural college students, and the coefficient is negative $(-0.06)$. The reason for this result may be that, different from the survival entrepreneurship carried out by laid-off workers in order to make a living, the entrepreneurship of college students is more opportunistic, that is, they have higher technical threshold and pay more attention to potential profit opportunities. Agricultural college students mainly study agriculture-related majors, and their core competitiveness and advantages are mainly concentrated in agriculture. Their future entrepreneurial field also points to agriculture. Entrepreneurs in the agricultural field have to some extent wiped out the difference between urban and rural areas where college students come from.

X3 family income has no significant influence on entrepreneurial intention of agricultural college students.

The influence coefficient of X4 entrepreneurial learning on entrepreneurial willingness of agricultural college students is 0.45 , which is significant at the level of $5 \%$, indicating that participation in entrepreneurial learning has a positive and significant impact on the increase of entrepreneurial willingness of college students. If the agricultural college students only master the knowledge of agricultural science and technology, but do not understand the basic situation of the agricultural market, do not know the basic operating rules of the agricultural market, they will not dare to venture. Through entrepreneurial learning, agricultural college students can understand the basic situation of the 
market, know how to identify and grasp entrepreneurial opportunities, how to obtain entrepreneurial resources, how to establish entrepreneurial teams, and how to consciously cultivate their own entrepreneurial qualities. The empirical results of this study show that entrepreneurial learning can significantly improve the entrepreneurial willingness of agricultural college students, and the advanced agricultural technology that agricultural college students have mastered is likely to be creatively applied in future entrepreneurial practice and accelerate the process of agricultural modernization.

$\mathrm{X} 5$ the coefficient of the influence of attention to entrepreneurial deeds on entrepreneurial intention of agricultural college students is 0.87 , which is significant at the level of $1 \%$.It shows that the more attention they pay to the entrepreneurial deeds, the higher their entrepreneurial willingness will be. Some people believe that entrepreneurial knowledge comes from entrepreneurial experience, that is, entrepreneurs keep accumulating their past entrepreneurial experience, constantly refine it and transform it into a systematic knowledge. If classroom entrepreneurship education belongs to cognitive learning, then refining and developing one's own entrepreneurial experience belongs to experiential learning. However, agricultural college students are still students in the first place. They have a lot of studies to complete first, so it is difficult for them to put all their energy into entrepreneurial practice. Therefore, college students' pay attention to entrepreneurial deeds, familiar with the stories of other entrepreneurs, understanding the entrepreneurial experience of other entrepreneurs, and summarizing their lessons can play the role of "Quasi-experience" learning.

The coefficient of the influence of X6 policy attention on the entrepreneurial intention of agricultural college students is 1.07 , which is significant at the level of $1 \%$.It shows that the more attention agricultural college students pay to entrepreneurial policies, the higher their entrepreneurial willingness will be. Good entrepreneurship policies are public goods provided by the government to encourage entrepreneurs to carry out entrepreneurial activities, create a good entrepreneurial environment and build a social atmosphere for entrepreneurship. Cai $\mathrm{Li}$ et al. (2007) analyzed the entrepreneurial environment from the perspective of resource dependence and believed that the entrepreneurial environment was constituted by the sum of various external factors that entrepreneurs could use and had to face in the process of entrepreneurship. Among them, entrepreneurial support policies played a positive role in the construction of the external environment and were an important part of the entrepreneurial environment. In the context of rural revitalization and agricultural modernization, the government has continuously introduced encouraging policies to support entrepreneurship in order to build a good entrepreneurial environment. The more agricultural college students pay attention to entrepreneurship policy, the more optimistic they are about the gradual improvement of the future entrepreneurial environment, the deeper they feel about the entrepreneurial atmosphere, and the higher their entrepreneurial willingness will be.

X7 The coefficient of the influence of family entrepreneurship on the entrepreneurial willingness of agricultural college students is 0.43 , which is significant at the level of $10 \%$, indicating that the more entrepreneurs in both parents, the higher the entrepreneurial willingness of students as children. Lu Xueyi (2001) divides rural elites into three categories, namely, political elite, economic elite and social elite. Those whose parents or one of them is a entrepreneur are generally classified as the economic elite. Family ethics and family culture have a profound influence in China (Fei Xiaotong 1984). Entrepreneurial culture or entrepreneurial consciousness can also be passed down from generation to generation through families. Compared with the elite families with entrepreneurial practice, the children of ordinary families with no entrepreneurial practice have different endowments in entrepreneurial culture. This difference in endowments is reflected in the level of entrepreneurial willingness. 
Table 2. Results of empirical analysis

\begin{tabular}{|c|c|c|c|c|}
\hline variable & coefficient $\mathrm{B}$ & standard error S.E. & Wals chi-square & significance \\
\hline $\mathrm{X} 1$ gender & 0.34 & 0.21 & 2.47 & 0.11 \\
\hline X2 Urban or rural & -0.02 & 0.25 & 0.01 & 0.93 \\
\hline $\begin{array}{l}\text { X3 Household } \\
\text { income }\end{array}$ & -0.06 & 0.13 & 0.20 & 0.64 \\
\hline $\begin{array}{l}\text { X4 Entrepreneurial } \\
\text { learning }\end{array}$ & $0.45 * *$ & 0.19 & 5.38 & 0.02 \\
\hline X5 Deeds attention & $0.87 * * *$ & 0.20 & 18.01 & 0.00 \\
\hline X6 Policy concern & $1.07 * * *$ & 0.22 & 23.53 & 0.00 \\
\hline $\begin{array}{l}\text { X7 Family } \\
\text { entrepreneur }\end{array}$ & $0.43 *$ & 0.25 & 2.81 & 0.09 \\
\hline constant & $-5.48 * * *$ & 0.87 & 39.75 & 0.00 \\
\hline
\end{tabular}

\section{CONCLUSIONS AND POLICY IMPLICATIONS}

At present, livelihood entrepreneurship is still the mainstream form of farmers' entrepreneurship in China. Agricultural entrepreneurship is still in its primary stage to a considerable extent (Fan Bowen), the opportunistic entrepreneurship which more emphasis on the application of advanced agricultural science and technology, its development level is not high. Livelihoods entrepreneurship is the forced entrepreneurship of entrepreneurs in order to make a living. It has its own stage limitations, such as ignoring long-term development and paying too much attention to short-term interests; Using simple and low technologies with quick results; the lack of a marketing strategy and the meagre profits, low management level and low efficiency, so on deficiencies. If entrepreneurship in the agricultural field stagnates in the stage of livelihood entrepreneurship, it will not be conducive to the development of agricultural modernization and the improvement of agricultural productivity. the opportunistic entrepreneurship which is more emphasize to the application of advanced agricultural science and technology, more emphasize to the future market profit, is the urgent requirements of rural revitalization and agricultural modernization. Only by transforming agricultural entrepreneurship into opportunistic entrepreneurship can we improve the quality of agricultural entrepreneurship and promote the development of agricultural modernization in China. And the main body of agricultural opportunistic entrepreneurship is the students of agricultural colleges and universities. Through empirical research, this paper draws the following conclusions: for agricultural college students who are potential subjects of agricultural opportunistic entrepreneurship, among the factors influencing their entrepreneurial intention, the urban-rural difference and family income have no significant influence. Entrepreneurial learning, attention to deeds, policy attention and family entrepreneurship all have positive effects on the increase of entrepreneurial willingness of agricultural college students.

Combined with the research conclusions of this paper, from the perspective of rural revitalization and agricultural modernization, the following policy implications are proposed. First of all, we should strengthen entrepreneurship education in agricultural colleges and universities. These colleges and universities gather young talents who devote themselves to the agricultural field. There are not only talents training in basic agricultural disciplines, but also original innovations in cutting-edge agricultural technologies. Strengthening entrepreneurship education in agricultural colleges and universities can enable future agricultural opportunistic entrepreneurs to make better use of advanced agricultural science and technology in their entrepreneurship process, accurately identify and deeply dig high-quality entrepreneurship 
opportunities, and then make agricultural entrepreneurship transform to a high standard and a high starting point, improve the quality of agricultural entrepreneurship, and accelerate the process of agricultural modernization. Secondly, further improve the entrepreneurial support policies, and strengthen financial institutions' entrepreneurial financial services for agricultural college students. To broaden the capital source channels for agricultural college students, agricultural colleges or rural collective economic organizations can increase the initial capital for them by means of investment and shareholding, so as to achieve mutual benefit and win-win results while dispersing entrepreneurial risks.

\section{REFERENCES}

[1] Wang Zhiwei, Wang Qingcai et al., Practical Research on Innovation and Entrepreneurship Education of Forestry College Students [J], Contemporary Educational Practice and Teaching Research, 2020,03.

[2] Li Linjie, Research on the Path to the Construction of Talent Training System of Innovation and Entrepreneurship Education in Colleges and Universities [J], Journal of Multimedia and Network Teaching in China, 2020,04

[3] Wang Wenlei, Hu Yunchu, et al., Study on the Construction of Curriculum System for Cultivating Innovation and Entrepreneurship Awareness of Graduate Students in Agricultural and Forestry Colleges [J], Science and Education, 2020,04.

[4] He Junxi, Research on the Impact of the Integration of Innovation and Entrepreneurship Education and Professional Education on College Students' Employability [D], Xiangtan University, 2019.

[5] Chen Cheng, The Impact of College Students' Entrepreneurship Education on Entrepreneurship Practice: An Empirical Study Based on the Innovation and Entrepreneurship Management Intensive Class of Zhejiang University [D], Zhejiang University, 2019.

[6] Peter Drucker, Innovation and Entrepreneurship [M], China Machine Press, Beijing, 2007.

[7] Schumpeter, Theory of Economic Development [M], The Commercial Press, Beijing.2020.

[8] Schultz, Transformation of Traditional Agriculture [M], The Commercial Press, Beijing.2003. 